\title{
POTRET PETANI MUDA \\ (Kasus Pada Petani Muda Komoditas Hortikutura di Kabupaten Bandung Barat)
}

\author{
R.A Budi Kusumo ${ }^{1 a}$ dan G.W Mukti ${ }^{1}$ \\ ${ }^{1}$ Staf Pengajar Program Studi Agribisnis Fakultas Pertanian Universitas Padjadjaran \\ Jl. Raya Jatinangor Sumedang Km 21 \\ ${ }^{a}$ Korespodensi: Rani Andriani Budi Kusumo, Email : raniandriani081@gmail.com
}

\begin{abstract}
BPS data shows a decrease in the number of people working in the agricultural sector and the age structure of farmers is dominated by older farmers. The decline in the number of farmer households in Indonesia is caused by several factors, including death or moving out of the agricultural sector, and on the other hand there are fewer new residents involved in the agricultural sector. However, an interesting phenomenon in West Bandung Regency is that horticulture farming is beginning to be sought after by young farmers. This study aimed to provide an overview of young farmers analyzed through the characteristics, perceptions, and background of young farmers in running horticulture farming in West Bandung Regency. This research was a quantitative research with survey techniques. Respondents in this study were 120 young farmers who were randomly selected. Data were analyzed descriptively. The results showed that there were still a few young farmers who were college graduates, have the land of $<0.5$ ha and not long enough to run farming. Most young farmers have parents who also work as farmers. The main factor that drives young farmers to engage in agriculture were parental and evirontment support and quite promising opportunities in the horticulture sub-sector.
\end{abstract}

Keywords : Farmer, Young, Horticulture

\begin{abstract}
ABSTRAK
Data BPS menunjukkan penurunan jumlah penduduk yang bekerja di sektor pertanian dan struktur umur petani didominasi oleh petani yang sudah berusia tua Menurunnya jumlah rumah tangga petani di Indonesia disebabkan oleh beberapa faktor, diantaranya adalah meninggal atau berpindah kerja ke luar sektor pertanian, dan di sisi lain jumlah penduduk yang baru masuk terlibat di sektor pertanian jumlahnya lebih sedikit. Namun fenomena yang menarik di Kabupaten Bandung Barat adalah usahatani hortikultura mulai diminati oleh petani muda Penelitian ini bertujuan untuk memberikan gambaran mengenai petani muda yang dianalisis melalui karakteristik, persepsi, dan latar belakang dalam menjalankan usahatani hortikultura di Kabupaten Bandung Barat. Penelitian ini merupakan penelitian kuantitatif dengan teknik survey. Responden dalam penelitian ini berjumlah 120 orang petani muda yang dipilih secara acak. Data dianalisis secara deskriptif kuantitatif. Hasil penelitian menunjukkan masih sedikit petani muda yang merupakan lulusan perguruan tinggi, sebagian besar menguasai lahan < 0,5 Ha dan belum cukup lama menjalankan usahatani. Sebagian besar petani muda memiliki orangtua yang juga berprofesi sebagai petani. Faktor utama yang mendorong petani muda untuk terjun dalam bidang pertanian adalah dukungan orangtua dan lingkungan serta peluang yang cukup menjanjikan pada subsektor hortikultura.
\end{abstract}

Kata Kunci : Petani, Muda, Hortikultura 



\section{PENDAHULUAN}

Data Sensus Pertanian tahun 2003 dan 2013 menunjukkan terjadi penurunan jumlah rumah tangga petani sekitar 5,10 juta (16 persen). Rumah tangga petani di Indonesia pada 2003 berjumlah 31,23 juta dan menurun menjadi 26,14 juta pada 2013. Lebih lanjut data Sensus Pertanian tahun 2013 menyebutkan bahwa jumlah petani berkurang sebanyak satu juta orang per tahun (BPS, 2013). Menurunnya jumlah rumah tangga petani di Indonesia disebabkan oleh beberapa faktor, diantaranya adalah meninggal atau berpindah kerja ke luar sektor pertanian, dan di sisi lain jumlah penduduk yang baru masuk terlibat di sektor pertanian jumlahnya lebih sedikit.

Selain permasalahan berkurangnya jumlah petani, hasil Sensus Pertanian tahun 2013 juga menunjukkan struktur umur petani didominasi oleh petani yang sudah berusia tua, $61,8 \%$ petani berusia di atas 65 tahun. BPS (2013) menyebutkan terjadi pergeseran persentase petani yang cenderung bergeser ke usia tua, hal ini mengindikasikan adanya fenomena aging farmer, yakni fenomena tenaga kerja di bidang pertanian didominasi oleh pekerja berusia tua. Setiawan et al (2018) menjelaskan banyaknya pemuda desa yang meninggalkan sektor pertanian disebabkan oleh penilaian para pemuda yang menganggap sektor pertanian tidak menguntungkan, kurang bergengsi, dan identik dengan kemiskinan. Para pemuda desa lebih memilih melakukan urbanisasi ke kota-kota besar yang dinilai memiliki status sosial yang lebih tinggi dan dapat lebih menjamin kehidupan. Fenomena tersebut tidak hanya terjadi di Indonesia, Callahan (2008) menyebutkan bahwa di Amerika Serikat selama tiga dekade terakhir terjadi penurunan jumlah petani muda (berusia di bawah 35 tahun) dari $15,5 \%$ pada tahun 1978 menjadi $5,8 \%$ pada tahun 2007 ; dan sebaliknya terjadi peningkatan jumlah petani tua (berusia di atas 55 tahun) dari 40,9\% pada tahun 1978 menjadi sekitar $60 \%$ pada tahun 2007

Pandangan generasi muda mengenai sektor pertanian terkait dengan faktor ekologis seperti yang dijelaskan oleh Brofenbrenner (1981) dan Berns (1997). Faktor ekologi manusia menggambarkan bagaimana sosialisasi dan dukungan bagi perkembangan seorang individu dengan menggambarkan interaksi sistem mikro, meso, ekso, dan makro. Kaitannya dengan regenerasi petani, lingkungan berperan dalam membentuk persepsi dan nilai generasi muda terhadap dunia pertanian.

Faktor komoditas yang diusahakan juga turut mempengaruhi pandangan akan dunia pertanian. Hasil penelitian Setiawan (2015) menunjukkan bahwa proporsi pemuda yang bertani lebih banyak ditemukan di dataran tinggi dibandingkan dengan dataran rendah. Lebih lanjut, Setiawan (2012) menyatakan bahwa proses regenerasi petani yang berjalan secara alami lebih terlihat signifikan di dataran tinggi (hortikultura) dibandingkan dengan di daerah dataran rendah (sawah/padi) dan dataran medium (palawija). Tingginya minat pemuda untuk berusahatani hortikultura dipengaruhi oleh komoditas hortikultura yang merupakan komoditas yang bernilai tinggi dan menjanjikan dari segi pendapatan dibandingkan dengan komoditas pangan (Susilowati, 2016).

Salah satu sentra produksi komoditas hortikultura di Jawa Barat adalah Kabupaten Bandung Barat. Komoditas yang banyak diusahakan oleh petani di Kabupaten Bandung Barat adalah sayuran. Beragam jenis sayuran diusahakan di Kecamatan Lembang, Parongpong dan Cisarua. Di antara isu mengenai kekhawatiran mengenai turunnya minat generasi muda untuk terjun di bidang pertanian, di Kabupaten Bandung Barat usahatani hortikultura banyak 
dilakukan oleh petani muda. Hal ini membawa harapan besar bagi regenerasi petani. Berdasarkan hal tersebut, penelitian ini bertujuan untuk memberikan gambaran mengenai petani muda, yang dianalisis melalui karakteristik, persepsi, dan latar belakangnya dalam menjalankan usahatani hortikultura di Kabupaten Bandung Barat.

\section{BAHAN DAN METODE}

Penelitian ini merupakan bagian dari penelitian yang berjudul "Penguatan Kapasitas Kewirausahaan Petani Muda Hortikultura Skala Kecil di Kecamatan Parongpong, Kabupaten Bandung Barat.

\section{Lokasi Penelitian}

Penelitian dilaksanakan di Kabupaten Bandung Barat yang merupakan salah satu kabupaten dengan jumlah petani sayuran organik terbanyak di Jawa Barat (BPS, 2016). Kecamatan yang menjadi tempat penelitian adalah Cisarua, Parongpong dan Lembang. Penelitian ini berfokus pada petani muda yang terdapat di ketiga kecamatan tersebut dengan kepemilikan lahan tidak lebih dari dua hektar (skala kecil). Penelitian ini menggunakan metode penelitian kuantitatif. Pendekatan kuantatif digunakan untuk lebih memahami fakta sosial yang menjadi fokus penelitian (Singarimbun \& Effendi, 2008).

\section{Jenis Data dan Teknik Pengumpulan Data \\ Data yang digunakan dalam} penelitian ini adalah data primer dan data sekunder. Data primer merupakan data yang diperoleh langsung dari petani muda yang memiliki usaha dalam bidang pertanian komoditas hortikultura di wilayah Kabupaten Bandung Barat. Data sekunder diperoleh dari Badan Pusat Statistik, Jurnal, buku dan sumber data lainnya.

Teknik pengumpulan data dilakukan melalui :
1. Wawancara (interview) dengan panduan kuesioner, yaitu melakukan komunikasi langsung secara verbal dengan menggali permasalahan

2. Pengamatan langsung (observasi), yaitu pengamatan langsung dilakukan untuk melihat lokasi objek penelitian serta melakukan pengumpulan data sekunder. Observasi ini juga dilakukan secara mendalam, dengan mengikuti kegiatan petani secara penuh dalam aktivitas usaha,

3. Studi pustaka dari jurnal bereputasi sebagai acuan untuk menganalisis data yang dihasilkan di lapangan.

Dalam penelitian ini variabel yang akan diteliti adalah :

1. Karakteristik petani muda meliputi : umur, tingkat pendidikan, pengalaman usahatani, luas dan status penguasaan lahan.

2. Persepsi petani muda terhadap dunia pertanian : pandangan petani muda terhadap usahatani yang dijalankan.

3. Latar belakang petani terjun di usahatani, dukungan lingkungan.

\section{Metode Pemilihan Sampel}

Penentuan sampel dilakukan dengan metode systematic random sampling. Untuk mendapatkan validitas yang tinggi, maka penentuan sampel sangat penting dalam penelitian ini. Strata dalam penelitian ini adalah petani muda yang berusia dibawah 40 tahun, berusahatani dalam sub bidang produk hortikultura di Kab.Bandung Barat. Kecamatan yang dipilih adalah kecamatan Lembang, Parongpong dan Cisarua. Ketiga kecamatan tersebut dipilih karena merupakan sentra hortikultura di Kabupaten Bandung Barat. Langkah selanjutnya adalah mengambil jumlah petani secara proporsional dari setiap kecamatan, sehingga total sample yang diteliti dalam penelitian ini adalah sebanyak 120 orang petani muda. 


\section{Analisis Data}

Analisis data ini dilakukan dengan menggunakan statistik deskriptif. Data yang diperoleh kemudian dikumpulkan dalam bentuk tabel distribusi frekuensi, disajikan, dianalisis dan diinterpretasikan untuk melihat persepsi dan motivasi petani muda di Kecamatan Parongpong, Lembang dan Cisarua.

\section{HASIL DAN PEMBAHASAN}

\section{Karakteristik Petani Muda}

Usia petani berkaitan dengan kemampuan fisik petani dan kemampuan petani untuk mengadopsi sebuah inovasi. Soekartawi (2005) menyebutkan bahwa petani yang berusia muda lebih memiliki semangat dan rasa ingin tahu yang besar, sehingga mendorong mereka untuk mengadopsi sebuah inovasi. Rata-rata umur petani muda di Kabupaten Bandung Barat adalah 34 tahun (Tabel 1).

Berdasarkan pendidikan formal yang ditempuh, terlihat bahwa petani muda di Kabupaten Bandung Barat ada yang menempuh pendidikan hingga tingkat sarjana, meskipun persentasenya kecil dibandingkan dengan petani yang menempuh pendidikan formal hanya hingga tingkat SMP.

Tabel 1. Karakteristik Petani Muda di Kabupaten Bandung Barat, 2018

\begin{tabular}{lcr}
\hline \multicolumn{1}{c}{ Karakteristik } & Jumlah (n) & Persentase $(\%)$ \\
\hline Umur (Tahun) & 21 & \\
$21-30$ & 99 & 82,50 \\
$31-40$ & 34,67 & \\
Rata-rata umur & & \\
Pendidikan Formal & 22 & 18,33 \\
Tamat SD & 43 & 35,83 \\
Tamat SMP & 36 & 30,00 \\
Tamat SMA & 4 & 3,33 \\
Akademi & 15 & 12,50 \\
Sarjana & & \\
Latar Belakang Pendidikan Pertanian & 14 & 11,67 \\
Ya & 106 & 88,33 \\
Tidak & & \\
Status Penguasaan Lahan & 61 & 50,83 \\
Milik & 59 & 49,17 \\
Sewa & & \\
Luas Penguasaan Lahan (Ha) & 82 & 68,33 \\
$<0,5$ & 26 & 21,67 \\
$0,5-1$ & 12 & 10,00 \\
$>1$ & & \\
Pengalaman Usahatani (Tahun) & 40 & 33,33 \\
$0-5$ & 39 & 32,50 \\
$6-10$ & 22 & 18,33 \\
$11-15$ & 14 & 11,67 \\
$16-20$ & 5 & 4,17 \\
$>20$ & &
\end{tabular}



Mukti (2017) menyebutkan bahwa tingkat pendidikan formal berkaitan dengan kemampuan petani untuk menerapkan inovasi. Petani dengan tingkat pendidikan yang lebih tinggi memiliki kecenderungan untuk berinovasi dalam usaha yang mereka jalankan, memiliki konsep dan model bisnis yang jelas.

Fakta yang menarik adalah sebagian besar petani tidak memiliki latar belakang pendidikan tinggi di bidang pertanian. Fenomena tersebut di satu sisi memberikan gambaran usahatani hortikultura merupakan usaha yang diminati generasi muda dan dinilai cukup menjanjikan, namun di sisi lain baru sebagian kecil tenaga kerja terdidik yang terjun dalam bidang pertanian. Hal ini sejalan dengan hasil kajian yang dilakukan oleh Koalisi Rakyat untuk Kedaulatan Pangan (KRKP) dan Direktotat Kajian Strategis dan Kebijakan Pertanian Institut Pertanian Bogor (2015) yang menunjukkan lulusan pendidikan tingi pertanian cenderung memasuki dunia kerja non pertanian dan meninggalkan tenaga kerja kurang berpendidikan/kurang terlatih di sektor pertanian.

Sebagian petani $(50,83 \%)$ berusahatani di lahan milik sendiri. Berdasarkan penuturan responden, sebagian petani mewarisi lahan dari orangtuanya meskipun luasannya terbatas. Untuk mengembangkan usaha, petani biasanya menyewa lahan yang letaknya tidak jauh dari lahan yang mereka miliki. Sebagian besar petani $(68,33 \%)$ menguasai lahan < $0,5 \mathrm{Ha}$. Meskipun penguasaan lahan terbatas namun petani dapat mengoptimalkan pendapatannya dengan menanam sayuran bernilai ekonomis tinggi.

Pada Tabel 1 dapat dilihat bahwa sebagian petani muda masih berada dalam tahap memulai berusahatani, dan mereka belum memiliki pengalaman yang cukup lama dalam berusahatani. Hal ini sejalan dengan hasil penelitian Rasmikayati et al
(2017) yang menunjukkan baru sebagian petani muda yang menjalankan usahanya dengan mapan. Pengalaman usahatani merupakan salah satu faktor yang menunjang kegiatan usahatani. Mosher dalam Hosen (2012) menyebutkan pengalaman usahatani dapat mempengaruhi petani dalam pengambilan keputusan. Meskipun sebagian besar petani muda belum memiliki pengalaman dalam berusahatani, namun dengan perkembangan teknologi dan keterbukaan mereka terhadap hal-hal baru, membantu petani muda dalam menjalankan usahanya.

\section{Latar Belakang Petani Muda Terjun ke Dunia Pertanian}

Dilihat dari latar belakang keluarga, sebagian besar petani muda $(78,33 \%)$ berasal dari keluarga petani (Tabel 2). Berdasarkan hasil wawancara, orangtua maupun kerabat responden sudah lama menjalankan usahatani komoditas hortikultura, dan sedari kecil mereka tumbuh dan berkembang di lingkungan petani.

Tabel 2. Latar Belakang Profesi Orang Tua Petani Muda

\begin{tabular}{lrr}
\hline & Jumlah (n) & Persentase (\%) \\
\hline Ya & 94 & 78,33 \\
\hline Tidak & 26 & 21,67 \\
\hline Jumlah & 120 & 100,00 \\
\hline
\end{tabular}

Keputusan petani muda untuk terjun ke bidang pertanian dilatarbelakangi oleh berbagai faktor. Dukungan keluarga dan lingkungan tempat tinggal merupakan faktor yang cukup mempengaruhi petani muda untuk berusahatani (Tabel 3). Hal ini sejalan dengan penjelasan pada Tabel 2, dimana responden memang tinggal di lingkungan petani, sehingga secara tidak langsung mereka mengenal dan belajar mengenai dunia pertanian. Adinugraha dan Herawati (2015) menjelaskan faktor lingkungan, 
terutama keluarga merupakan actor utama dalam mewariskan nilai-nilai pertanian terhadap anak. Lebih lanjut, Kusumo, et al (2016) menyebutkan bahwa secara sosiologis, lingkungan yang sudah dikenal atau lingkungan yang sesuai dengan kemampuan seorang individu akan membuat seseorang merasa lebih nyaman untuk mencari nafkah. Kebiasaan dan pola kehidupan yang berulang di lingkungan repsonden, mendorong petani muda untuk menjalankan usahatani hortikultura.

Komoditas yang diusahakan juga turut mempengaruhi dukungan orangtua terhadap keputusan anaknya untuk menjadi petani. Studi yang dilakukan oleh Koalisi Rakyat untuk Kedaulatan Pangan dan
Oxfam (diacu dalam Ambarwati et al, 2016) menunjukkan bahwa secara umum petani padi cenderung tidak menginginkan anaknya menjadi petani, sementara petani hortikultura cenderung mendorong anaknya untuk berusahatani hortikultura. Hal tersebut berkaitan dengan harga komoditas dan peluang untuk keuntungan yang lebih baik. Sejalan dengan hal tersebut, petani muda pada kelompok ini cenderung memandang pertanian sebagai usaha yang menjanjikan (Tabel 4). Mereka telah melihat keberhasilan orang tua dan juga petani lain di lingkungan tempat tinggal nya, sehingga mereka tertarik menjadikan profesi petani sebagai pilihan untuk mencari nafkah

Tabel 3. Alasan Petani Muda Untuk Terjun Dalam Bidang Pertanian, 2018

\begin{tabular}{lrr}
\hline \multicolumn{1}{c}{ Alasan } & Jumlah (n) & Persentase (\%) \\
\hline Melihat Peluang & 32 & 26,67 \\
Hobi & 9 & 7,50 \\
Dorongan Keluarga & 40 & 33,33 \\
Lingkungan tempat tinggal & 24 & 20,00 \\
Kebutuhan ekonomi & 15 & 12,50 \\
Jumlah & 120 & 100,00 \\
\hline
\end{tabular}

Bagi petani muda yang tidak berasal dari lingkungan petani, peluang dan hobi merupakan faktor yang lebih berpengaruh untuk mendorong mereka terjun dalam dunia pertanian (Tabel 3). Karakteristik petani muda pada kelompok ini adalah mereka bertindak sebagai entrepreneur, yaitu petani yang mampu untuk mengidentifikasi dan mengeksploitasi peluang - peluang pasar yang ada dan bernilai tinggi dengan memanfaatkan sumber daya pertanian yang dimiliki oleh petani dengan cara yang fleksibel dan inovatif. Mukti, et al (2017); Rasmikayati et al (2017) menjelaskan petani muda yang inovatif berorientasi meningkatkan kualitas produk melalui proses produksi yang baik dan benar. Informasi pasar menjadi hal yang sangat penting untuk mengetahui kebutuhan dan keinginan konsumen, sehingga inovasi produk yang petani lakukan selalu mengikuti kebutuhan pasar. Selain inovasi produk, petani muda juga banyak melakukan inovasi dalam hal pemasaran. Pemasaran melalui media sosial merupakan salah satu cara yang ditempuh petani untuk menjual produk kepada masyarakat, terutama yang tinggal di perkotaan. Dalam hal kelembagaan, sebagian petani muda menjalankan usahanya secara berkelompok, dengan tujuan agar lebih mudah berbagi informasi, berbagi peran dan juga berbagi resiko dalam usahatani. Petani pada kelompok ini juga memandang pertanian sebagai usaha yang menjanjikan dari segi pendapatan (Tabel 4). Hal ini sejalan dengan alasan utama mereka untuk terjun dalam bidang pertanian adalah karena melihat 
peluang yang besar dalam bisnis ini. Anwarudin dan Haryanto (2018) menjelaskan bahwa minat yang tinggi pada generasi muda untuk berusaha tani salah satunya didorong oleh berkembangnya pasar hasil pertanian. Lebih lanjut, Mukti, et al
(2017) menjelaskan petani muda yang inovatif melihat pertanian sebagai bisnis yang nyata, dapat menghasilkan keuntungan dan dapat menjadi sandaran hidup bagi pelaku di dalam bisnis ini.

Tabel 4. Persepsi Petani Muda Terhadap Pekerjaan di Bidang Pertanian, 2018

\begin{tabular}{lcccc}
\hline \multicolumn{1}{c}{$\begin{array}{c}\text { Alasan Terjun ke Bidang } \\
\text { Pertanian }\end{array}$} & Menjanjikan & $\begin{array}{c}\text { Persepsi Terhadap Bidang Pertanian } \\
\text { Pekerjaan Turun } \\
\text { Temurun }\end{array}$ & Biasa Saja & Melelahkan \\
\hline Melihat Peluang & $25,00 \%$ & $0,83 \%$ & $0,83 \%$ & \\
Hobi & $5,83 \%$ & & $1,66 \%$ & \\
Dorongan Keluarga & $17,50 \%$ & $3,33 \%$ & \\
Lingkungan tempat tinggal & $15,00 \%$ & $0,83 \%$ & $4,17 \%$ & \\
Kebutuhan ekonomi & $3,33 \%$ & $3,08 \%$ & $5 \%$ & $0,83 \%$ \\
\hline
\end{tabular}

Sebagian kecil petani muda $(12,5 \%)$ kelompok terakhir adalah mereka yang terjun ke usaha pertanian karena sematamata kebutuhan ekonomi dan sulit mencari pekerjaan di bidang lain (Tabel 3). Berdasarkan hasil wawancara diketahui sebagian besar petani pada kategori ini memiliki orangtua yang juga berprofesi sebagai petani dan pada awalnya mereka kurang memiliki keinginan untuk berprofesi sebagai petani. Hal ini disebabkan karena mereka melihat dan sering mendengar penuturan dari orangtua mereka bahwa menjadi petani itu kurang menjanjikan, namun karena orangtua mewariskan sebidang lahan mereka kemudian mencoba memanfaatkan lahan tersebut untuk diusahakan.

Sukayat dan Supyandi (2017) menyebutkan keputusan pemuda untuk memasuki sektor pertanian terkait dengan persepsi, motivasi dan kemampuan atau pengetahuan. Pada kelompok ini, terlihat persepsi petani melihat bidang pertanian semata-mata adalah karena "warisan" dan "terpaksa” menjalankannya (Tabel 4).

\section{KESIMPULAN DAN IMPLIKASI KEBIJAKAN}

Kesimpulan

Secara umum minat generasi muda untuk menjalankan usahatani hortikultura memberikan harapan yang menggembirakan di tengah-tengah krisis regenerasi petani, meskipun para petani tersebut belum begitu mapan dalam menjalankan usahanya dan masih kurangnya lulusan pendidikan tinggi pertanian yang terlibat di sektor ini. Faktor utama yang mendorong petani muda untuk terjun dalam bidang pertanian adalah dukungan orangtua dan lingkungan serta peluang yang cukup menjanjikan pada subsector hortikultura. Untuk mendukung minat generasi muda pada sektor pertanian diperlukan dukungan kepada petani muda untuk meningkatkan kualitas petani dan menumbuhkan usahatani yang inovatif di pedesaan.

\section{Daftar Pustaka}

Adinugraha, Y., Herawati, R. 2015. Menguak realitas orang muda pertanian di pedesaan. Jurnal Analisis Sosial, 19(1) : 27-38. 
Ambarwati, L., Harahap, R.A., Sadoko, I. White, B. 2016 Land tenure and agrarian structure in regions of small scale food production. Singapore : NUS Press

Anwarudin, O., Haryanto, Y. 2018. The role of farmer-to-farmer extension as a motivator for the agriculture young generation. International Journal of Sociaal Science and Economic Research, 3(1) : 428-437.

Berns, R. M. 1997. Child, Family, School, Community. Socialization and Support. Orlando : Hartcourt Brace College Publishers.

Bronfenbrenner, U. 1981. The Ecology of Human Development : Experiment By Nature and Design. USA : Library of Congress Cataloging in Pubication Data.

Callahan, Joe. 2008. Youth Leaving Land to Pursue Other Careers. McClatchy Tribune Business News. Washington : Tribune Content Agency LLC

Hosen, N. 2012. Adopsi teknologi pengolahan limbah pertanian oleh petani anggota Gapoktan Puap di Kabupaten Agam, Sumatera Barat. Jurnal Pertanian Terapan, 12(2): 8995.

Koalisi Rakyat untuk Kedaulatan Pangan (KRKP) dan Direktorat Kajian Strategis dan Kebijakan Pertanian IPB. 2015. Kajian regenerasi petani pada keluarga petani padi dan hortikultura. Laporan Penelitian.
Mukti, G.M., Kusumo, R.A.B., Qanti, S.R. 2017. Perilaku sukses petani muda wirausaha lulusan Fakultas Pertanian Universitas Padjadjaran. Jurnal Agribisnis Terpadu, 10(2) : 221-234.

Rasmikayati, E., Setiawan, I., Saefudin, B.R. 2017. Kajian karakteristik, perilaku dan faktor pendorong petani muda terlibat daam agribisnis pada era pasar global. Mimbar Agribisnis, 3(2) : 134-149.

Setiawan, I. 2012. Agribisnis Kreatif : Pilar Usaha Wirausaha Masa Depan, Kekuatan Dunia Baru Menuju Kemakmuran Hijau. Jakarta (ID) : Penebar Swadaya.

Setiawan, I. 2015. Perkembangan kemandirian pelaku brain gain sebagai alternatif inovasi regenerasi pelaku agribisnis di dataran tingg $i$ Jawa Barat. (Disertasi) Sekolah Pascasarjana. IPB. Bogor.

Soekartawi. 2005. Prinsip Dasar Komunikasi Pertanian. Jakarta (ID) : UI - Press.

Sukayat, Y., Supyandi, D. 2017. Perilaku pemuda desa dalam kegiatan pertanian. Jurnal Ilmu Pertanian dan Peternakan, 5(1) : 49-55.

Susilowati, S.S. 2016 Fenomena penuaan petani dan berkurangnya tenaga kerja muda serta implikasinya bagi kebijakan pembangunan pertanian. Forum Penelitian Agro Ekonomi, $34(1): 35-55$ 